\title{
Development of a New Method for Whole-Body Working Postures: K-OWAS
}

\author{
Yu-Chang Kim, Dae-Su Kim \\ Department of Industrial Management Engineering, Dong-Eui University, Busan, 614-714
}

\begin{abstract}
Objective: The aim of this study is to develop new K-OWAS on the basis of the anthropometry of Koreans considering works in shipbuilding and heavy industry for evaluation whole-body working postures. Background: Work Related Musculoskeletal Disorders(WMSDs) were a leading cause of sick leaves and injuries in the industries of our country. Especially, awkward working postures and handling of heavy weight are known as a main cause of WMSDs. OWAS, RULA and REBA are much used as the method for evaluating the awkward working postures. OWAS is the working postures evaluation method that can be used for the evaluation of whole-body working postures. OWAS was the method made based on the anthropometry of the foreigner, working postures and weight does not fit our work state. Method: This method was evaluated considering the anthropometry of the Koreans, working postures and weight in shipbuilding and heavy industry work state in Korea. Results: Correlation of action level of OWAS and subjective discomfort for each body parts were not statistically significant $(p \geq 0.1)$. But correlation of action level of K-OWAS and subjective discomfort for torso and waist were statistically significant $(p \leq 0.1)$. Conclusion: K-OWAS was suitable in the evaluation of upper body including torso and waist. Application: New method for whole-body working postures from this study prevent WMSDs and help improvement of working environment and design of working method.
\end{abstract}

Keywords: K-OWAS, OWAS, 3DSSPP, Compression force

\section{Introduction}

우리나라 전 산업에 걸쳐서 사회적 이슈로 대두되고 있는 작업관련성 근골격계질환(Work related Musculoskeletal Disorders: WMSDs)은 다양한 작업에서 발병 가능성이 높 으며, 이로 인한 작업자의 건강 및 경제적인 측면에서 큰 손 실을 초래하고 있다. 노동집약적인 작업 환경을 가지는 제조 업, 자동차 조립(자동차 제조업), 조선업, 농작업 등에서 많 은 근골격계질환이 발생하고 있고, 그 원인은 부적절한 작업 자세, 힘, 반복 등이 원인으로 알려져 있다(Kim and Jung, 2000). 특히, 부적절한 작업 자세는 중량물 취급과 함께 근 골격계질환의 주요 원인으로 알려져 있다(Kim and Jang, 2008).
NIOSH(1997)는 600건 이상의 역학적 연구(Epidemiological Study) 와 관련된 문헌 조사 결과를 바탕으로 목, 어깨, 허리 부위의 근골격계질환 발병은 부적절한 작 업 자세와 인과 관계가 있음을 보고하였다(Waters et al., 1993). 부적절한 작업 자세의 개선을 위해서는 작업 자세에 따른 작업 부하의 예측 및 평가가 선행되어야 한다. 부적절 한 작업 자세를 평가하기 위한 방법으로는 관찰적 작업 자 세 평가 기법(Observational Posture Evaluation Method) 이 많이 사용되고 있다. 관찰적 작업 자세 평가 기법은 사용 이 간단하면서 비용이 저렴하고, 작업 자세 부하에 대해 신 뢰할 수 있는 정보를 얻을 수 있다는 장점이 있다(Genaidy et al., 1994).

현재까지 다수의 관찰적 작업 자세 평가 기법이 개발되고 있으나 국내에서는 OWAS, RULA, REBA가 많이 사용되고

Corresponding Author: Yu-Chang Kim. Department of Industrial Management Engineering, Dong-eui University, Busan, $614-714$.

Mobile: 018-451-6114, E-mail: yckim@deu.ac.kr

Copyright@2012 by Ergonomics Society of Korea(pISSN:1229-1684 eISSN:2093-8462). All right reserved. 
있다(Moon et al., 2005). 그 중 OWAS는 전신작업의 평가 에 이용할 수 있는 작업 자세 평가 기법으로 대부분의 조선 업과 중공업에서 광범위하게 사용되고 있다.

OWAS (Ovako Working Posture Analysis System)는 핀란드의 철강회사인 Ovako 사에 의해 1970년대 중반에 개발된 후에 Ovako 사와 핀란드 산업보건연구원 $(\mathrm{FIOH})$ 이 공동으로 수정하여 개발한 대표적인 작업 자세 평가 기법이 다(Karhu et al., 1977; Scott and Lambe, 1996).

OWAS는 작업자들의 부적절한 작업 자세를 정의하고 평 가하기 위해 개발한 방법으로 작업자의 자세를 일정간격으 로 관찰하여 분석하는 작업 샘플링 (Work Sampling)에 기 본을 두고 있다. OWAS 평가 방법에는 허리, 팔, 다리의 자 세와 무게 항목에 따라 평가 항목별로 4가지 위험 수준으로 분류한다. 수준 1 은 안전한 작업, 수준 2 는 지속적인 관찰을 요하는 작업, 수준 3 은 개선을 요하는 작업, 수준 4 는 즉시 개선을 요하는 작업으로 평가된다.

자세 유지 등과 같은 정적 작업에는 근육활동도인 $\mathrm{EMG}$ 를 측정하여 평가를 하여야 하는 것이 적합하지만 이러한 평가 방법에는 복잡하고 고가인 특별한 장비를 사용하여야 하기 때문에 산업 현장에 사용하기가 어렵다. 그래서 산업 현장에 서는 측정기기를 이용하지 않고 간단한 작업 자세 관찰 등을 근거로 한 OWAS와 같은 간단한 평가 방법을 이용하고 있 다(Kim, 2011).

OWAS는 특별한 도구를 필요로 하지 않으며, 현장에서 기록 및 해석할 수 있고, 평가 기준을 완비하고 있으며 간 편하게 평가할 수 있다. 그러나 OWAS는 외국인의 인체계 측을 바탕으로 만들어진 평가 기법이며, 작업 자세와 무게 도 한국의 작업 현황과 맞지 않는 부분이 존재하고 있다. OWAS 등 관찰적 기법들은 외부 부하인 무게를 고려하고 있지만, 그 분류 구간이 클 뿐만 아니라 자세 부하의 평가 에 초점이 맞추어져 객관적 근거가 부족하다(Kee \& Park, 2005). 또한 다리 자세의 분류 구간이 넓고 무게가 맞지 않 아서 조선업과 중공업에서 사용하는데 불편함이 따른다.

따라서, 본 연구는 기존의 OWAS 평가 기법을 한국인 의 인체계측을 바탕으로 한국의 조선업과 중공업 작업 현 황과 밀접한 작업 자세, 무게 등을 고려하여 새로운 형태의 OWAS를 개발하였다. 이 연구의 결과를 바탕으로 조선업과 중공업에서 발생하는 전신작업을 평가할 수 있는 한국형 전 신작업 평가 기법인 $\mathrm{K}-\mathrm{OWAS}$ 를 개발하고 평가하고자 한다.

\section{New Model}

한국인의 인체특성에 맞는 전신작업 평가를 위해 기존의
OWAS를 변형한 한국형 $\mathrm{K}-\mathrm{OWAS}$ 의 자세한 모형은 다음 과 같다.

\subsection{K-OWAS model}

\subsubsection{Working posture and code system}

기존의 OWAS 작업 자세와 코드체계를 문헌 조사, 현장 조사, 전문가의 의견을 토대로 한국의 작업 현황에 맞게 수정 하였다. 일반적으로 조선업과 중공업에서 가장 빈번하게 발 생하는 허리와 팔에 대한 작업 자세는 4 개와 3 개로 OWAS 와 동일하게 분류하였다.

$\mathrm{OWAS}$ 는 다리 자세의 분류 수가 7 개로 많아 평가에 어려 움이 있다고 알려져 있기 때문에 다리에 대한 작업 자세는 $\mathrm{K}-\mathrm{OWAS}$ 에서는 3 개로 분류하였다.

OWAS에서 외부 부하로 무게를 3 개로 분류하지만 그 분류 구간이 크기 때문에 한국 작업 상황에 적합하지 않다 (Kee and Park, 2005). 또한, 중량물 기준이 $5 \mathrm{~kg}$ 이상인 것을 고려하여 $\mathrm{K}-\mathrm{OWAS}$ 에서는 세분화하여 4 개로 분류하 였다.

Table 1은 허리, 팔, 다리, 무게에 대한 작업 자세 분류 및 코드체계를 보여준다.

Table 1. K-OWAS codes for different body parts

\begin{tabular}{c|c|l}
\hline Body parts & Code & Description of postures \\
\hline \multirow{4}{*}{ Back } & 0 & Straight \\
\cline { 2 - 3 } & 1 & Bent \\
\cline { 2 - 3 } & 2 & Twisted \\
\cline { 2 - 3 } & 3 & Bent and twisted \\
\hline \multirow{4}{*}{ Arms } & 0 & Both below shoulder level \\
\cline { 2 - 3 } & 1 & One above shoulder level \\
\cline { 2 - 3 } & 2 & Both above shoulder level \\
\hline \multirow{4}{*}{ Legs } & 0 & Both straight \\
\cline { 2 - 3 } & 1 & One straight and One bent \\
\cline { 2 - 3 } & 2 & Both bent and Kneeling \\
\hline \multirow{4}{*}{ Weight } & 0 & 0kg over $\sim 5 \mathrm{~kg}$ under \\
\cline { 2 - 3 } & 1 & $5 \mathrm{~kg}$ over $\sim 10 \mathrm{~kg}$ under \\
\cline { 2 - 3 } & 2 & $10 \mathrm{~kg}$ over $\sim 15 \mathrm{~kg}$ under \\
\cline { 2 - 3 } & 3 & $15 \mathrm{~kg}$ over \\
\hline
\end{tabular}

\subsubsection{K-OWAS codes for different body parts}

$\mathrm{K}$-OWAS 신체 부위의 분류는 허리에서 4 개, 팔, 3 개, 다리 3 개, 무게 4 개로 구성되어 있다. 허리에서 4 개의 자세 는 각각 $0,1,2,3$ 의 코드를 할당 받았는데 이 코드가 곧 허 
리의 4 개 자세에 대한 위험도 점수가 되는 것이다. 그러므로 허리에서 코드 0 인 "곧바로 편 자세"는 위험도 점수가 0 점 이 되는 것이고, 코드 1 인 "상체를 앞으로 굽힌 자세"는 위 험도 점수가 1 점, 코드 2 인 "바로 서서 허리를 비튼 자세" 는 2점, 코드 3 인 "상체를 앞으로 굽힌 채 옆으로 비튼 자 세"는 위험도 점수가 3 점이 되는 것이다. 이러한 체계는 팔, 다리, 무게에서도 동일하게 적용된다. 각 자세 별로 각 코드 에 할당된 점수를 합하여 최종 위험도를 산출하였다.

\subsubsection{K-OWAS Action Category(AC)}

기존의 OWAS에서 $\mathrm{AC}$ 판정은 실제 작업 자세를 OWAS 의 코드에서 찾은 4 가지 점수(허리, 팔, 다리, 무게)를 가지 고 $\mathrm{AC}$ 판정표에서 $\mathrm{AC}$ 점수를 찾는다. 반면 $\mathrm{K}-\mathrm{OWAS}$ 는 이러한 불편을 해결하기 위하여 실제작업 자세에 해당하는 신체 부위(허리, 팔, 다리, 무게)의 코드를 합하여 $\mathrm{AC}$ 점수 를 구할 수 있도록 고안하였다.

예를 들면, 허리가 코드 0 인 "곧바로 편 자세"는 위험 수 준이 0 점이고, 팔이 코드 1 인 "한 팔만 어깨 위로 올린 자 세"는 1점이고, 다리가 코드 2 인 "쪼그린 및 무릎 꼻은 자 세"는 2점이고, 무게가 코드 3인 "10kg 이상 15kg 미만" 은 3점이기 때문에 각 자세의 위험 수준의 합은 6점으로 $\mathrm{K}-\mathrm{OWAS}$ 조치단계 $\mathrm{AC} 3$ 이 된다. 이처럼 $\mathrm{K}-\mathrm{OWAS}$ 는 특 별한 도구나 판정표 없이 각 작업 자세 코드의 합으로 $\mathrm{AC}$ 를 판정할 수 있기 때문에 작업 현장에서 유용하게 사용할 수 있다는 장점이 있다.

조치단계 분류의 자세한 내용은 Table 2와 같고, Figure 1 은 $\mathrm{K}-\mathrm{OWAS} \mathrm{AC}$ 판정표다.

Table 2. K-OWAS action categories for evaluation of working postures

\begin{tabular}{c|c|c}
\hline $\begin{array}{c}\text { K-OWAS } \\
\text { category }\end{array}$ & $\begin{array}{c}\text { Total of } \\
\text { risk level }\end{array}$ & Description \\
\hline AC 1 & $0,1,2,3$ & Not harmful - no action \\
\hline AC 2 & 4,5 & Some strain - near future \\
\hline AC 3 & 6,7 & Major strain - as soon as possible \\
\hline AC 4 & $8,9,10$ & Harmful - do at once \\
\hline
\end{tabular}

\section{Validation of New Model}

위에서 개발된 $\mathrm{K}-\mathrm{OWAS}$ 를 기존의 OWAS와 비교 평가 하기 위하여 피실험자들을 대상으로 실험을 진행하였으며, 모형 평가에 대한 자세한 내용은 다음과 같다.

\begin{tabular}{|c|c|c|c|c|c|c|c|c|c|c|c|c|c|}
\hline \multicolumn{14}{|c|}{ K-OWAS Action Category table } \\
\hline \multirow{2}{*}{\multicolumn{2}{|c|}{ Code }} & \multicolumn{4}{|c|}{0} & \multicolumn{4}{|c|}{1} & \multicolumn{4}{|c|}{2} \\
\hline & & 0 & 1 & 2 & 3 & 0 & 1 & 2 & 3 & 0 & 1 & 2 & 3 \\
\hline & 0 & 1 & 1 & 1 & 1 & 1 & 1 & 1 & 2 & 1 & 1 & 2 & 3 \\
\hline & 1 & 1 & 1 & 1 & 2 & 1 & 1 & 2 & 1 & 1 & 2 & 2 & 3 \\
\hline & 2 & 1 & 1 & 2 & 2 & 1 & 2 & 2 & 3 & 2 & 2 & 3 & 3 \\
\hline \multirow{3}{*}{1} & 0 & 1 & 1 & 1 & 2 & 1 & 1 & 2 & 2 & 1 & 2 & 2 & 3 \\
\hline & 1 & 1 & 1 & 2 & 2 & 1 & 2 & 2 & 3 & 2 & 2 & 3 & 3 \\
\hline & 2 & 1 & 2 & 2 & 3 & 2 & 2 & 3 & 3 & 2 & 3 & 3 & 4 \\
\hline \multirow{3}{*}{2} & 0 & 1 & 1 & 2 & 2 & 1 & 2 & 2 & 3 & 2 & 2 & 3 & 3 \\
\hline & 1 & 1 & 2 & 2 & 3 & 2 & 2 & 3 & 3 & 2 & 3 & 3 & 4 \\
\hline & 2 & 2 & 2 & 3 & 3 & 2 & 3 & 3 & 4 & 3 & 3 & 4 & 4 \\
\hline \multirow{3}{*}{3} & 0 & 1 & 2 & 2 & 3 & 2 & 2 & 3 & 3 & 2 & 3 & 3 & 4 \\
\hline & 1 & 2 & 2 & 3 & 3 & 2 & 3 & 3 & 4 & 3 & 3 & 4 & 4 \\
\hline & 2 & 2 & 3 & 3 & 4 & 3 & 3 & 4 & 4 & 3 & 4 & 4 & 4 \\
\hline
\end{tabular}

Figure 1. K-OWAS Action Category table

\subsection{Subject}

피실험자는 과거 병력 상 전신, 어깨, 허리, 무릎, 발목의 관절 운동범위에 제한이 없으며, 피로, 통증, 지각이상 등의 근골격계장애가 없는 5명의 20대 남자 대학생을 대상으로 하였다. 성별에 따른 차이를 없애기 위하여 전원 남성으로 선정하였다. 피실험자의 평균 나이는 24.8 세, 평균 신장은 $172 \mathrm{~cm}$, 평균 몸무게는 $67.4 \mathrm{~kg}$ 이었다.

\subsection{Evaluation of subjective discomfort and body parts}

주관적 불편도 평가는 Borg's CR-10 Scale을 사용하였 다(Borg, 1993). 이 평가 방법은 주관적 불편도를 평가하는 심물리학적 방법의 일종으로 0 10점 사이의 평가 구간을 갖는다. 주관적 불편도 평가는 전신작업 시 주로 사용되는 전신, 허리, 무릎 및 발목 부위에 대하여 실시하였다.

\subsection{Design of experimental variable}

본 연구에서 독립변수는 5종류의 작업 자세를 OWAS, $\mathrm{K}-\mathrm{OWAS}$ 로 평가한 조치단계로 선정하였다. 독립변수로 선 정된 5종류의 작업 자세는 우리나라 조선업과 중공업에서 가장 빈번하게 발생하는 작업 자세로 작업의 근골격계질환 관련 인간공학적 위험성을 조사하기 위하여 작업 현장에서 직접 촬영한 동영상과 인간공학적 작업 환경 조사도구를 토 대로 분석된 대표적인 자세들로 구성되었다. Figure 2는 독 립변수로 선정된 5종류의 작업 자세를 피실험자를 대상으로 평가하고 있는 샘플 그림이다.

종속변수는 전신, 허리, 무릎, 발목에 대한 주관적 불편도 의 평균값으로 선정하였다. 본 연구에서 선정된 독립변수와 종속변수는 다음 Table 3 과 같다. 


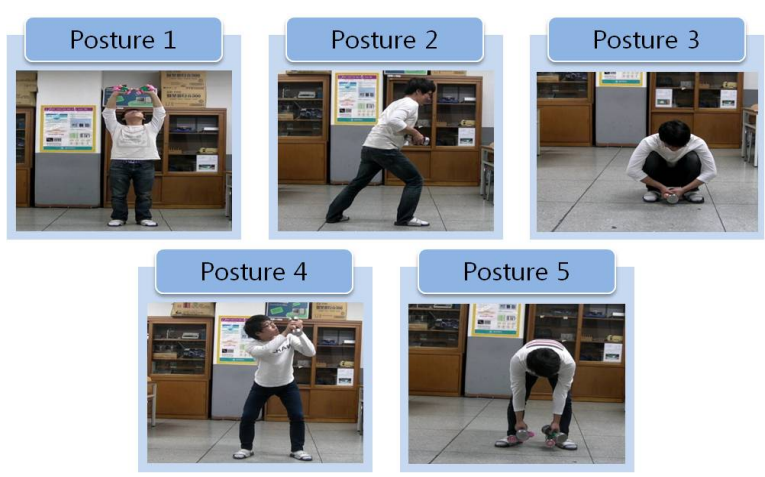

Figure 2. Working postures of 5 types

Table 3. Independent variable and dependent variable

\begin{tabular}{c|c}
\hline Classification & Description \\
\hline $\begin{array}{c}\text { Independent } \\
\text { variable }\end{array}$ & $\begin{array}{c}\text { Working postures of 5 types } \\
\text { (4 minutes for static posture) }\end{array}$ \\
\hline $\begin{array}{c}\text { Dependent } \\
\text { variable }\end{array}$ & $\begin{array}{c}\text { Average of subjective discomfort ratings } \\
\text { (Borg's CR-10 Scale) }\end{array}$ \\
\hline
\end{tabular}

자세 1: 두 다리를 펴고 선 자세로 상체를 똑바로 펴고 양 팔을 어깨위로 올린 자세(무게: $5.5 \mathrm{~kg}$ )

자세 2: 두 다리를 펴고 선 자세로 상체를 앞으로 굽히고 양 팔을 어깨 아래로 내린 자세(무게: $18 \mathrm{~kg}$ )

자세 3: 양 팔을 어깨 아래로 내리고 쪼그린 상태로 상체를 앞으로 굽힌 자세(무게: $3.5 \mathrm{~kg}$ )

자세 4: 양 팔을 어깨 아래로 내리고 한 쪽 다리에 힘을 주 고 상체를 앞으로 굽힌 채 옆으로 비튼 자세(무게: $3.5 \mathrm{~kg})$

자세 5: 양 팔을 어깨 위로 올리고 쪼그린 상태에서 상체를 앞으로 굽힌 채 옆으로 비튼 자세(무게: $3.5 \mathrm{~kg}$ )

\subsection{Method}

본 실험에서는 5 종류의 작업 자세에 따른 주관적 불편도 를 평가하기 위해 피실험자는 Borg's CR-10 Scale(Borg, 1993)을 이용하여 인지된 불편도를 평가하였다. 실험은 Figure 3 에서 제시한 각각의 실험조건에서 4 분간 정적인 자 세를 유지한 후 Borg's CR-10 Scale을 이용하여 주관적 불 편도를 평가하였다.

상지 자세에 대한 무게 부하는 실제 작업 현장, Figure 2 의 작업 자세에서 사용되는 공구 및 부자재의 실제 무게를 사용하였다. 각 피실험자들은 각기 다른 순서로 5종류의 작 업 자세를 취하였으며, 모든 자세는 무작위로 배정하였고, 각 자세에 대한 주관적 불편도 평가 후 피실험자들이 충분히 휴식을 취하였다고 확인한 후 실험을 계속 진행하였다.

그리고 5종류의 작업 자세의 조치단계를 평가하기 위하여 OWAS 평가 기법에 숙달된 연구원에게 $\mathrm{K}-\mathrm{OWAS}$ 의 평가
기법을 숙지 시킨 후 실험에 참여하게 하여 5종류의 작업 자세의 조치단계를 평가하도록 하였다. 그리고 실험에 참여 한 연구원이 평가한 조치단계와 주관적 불편도의 평균값을 결과의 분석에 이용하였다.

\subsection{Result of model evaluation}

새로운 전신작업 모형 평가 결과의 분석에는 5 명의 피실 험자들이 작성한 Borg's CR-10 Scale의 전신, 허리, 무릎, 발목에 대한 평균값과 작업 자세 평가 기법에 숙달된 연구원 이 평가한 OWAS, $\mathrm{K}-\mathrm{OWAS}$ 의 조치단계 점수를 이용하 였다.

자료의 통계처리 및 분석은 통계 프로그램인 Minitab 16 을 사용하였고 각 신체 부위별 주관적 불편도와 5 종류의 작 업 자세에 따른 OWAS, K-OWAS 조치단계의 상관관계 분석 결과는 다음 Table 4 와 같다.

Table 4. Correlation of action category and subjective discomfort

\begin{tabular}{c|c|c|c}
\hline $\begin{array}{c}\text { Evaluation } \\
\text { method }\end{array}$ & Body parts & $\begin{array}{c}\text { Correlation } \\
\text { coefficient }\end{array}$ & $P$-value \\
\hline \multirow{4}{*}{ OWAS } & Torso & 0.404 & 0.500 \\
\cline { 2 - 4 } & Waist & 0.499 & 0.392 \\
\cline { 2 - 4 } & Knee & 0.233 & 0.706 \\
\cline { 2 - 4 } & Ankle & 0.248 & 0.688 \\
\hline \multirow{4}{*}{ K-OWAS } & Torso & $\mathbf{0 . 9 3 5}$ & $\mathbf{0 . 0 2 0}^{* *}$ \\
\cline { 2 - 4 } & Waist & $\mathbf{0 . 8 1 2}$ & $\mathbf{0 . 0 9 5}^{*}$ \\
\cline { 2 - 4 } & Knee & 0.381 & 0.527 \\
\cline { 2 - 4 } & Ankle & 0.151 & 0.808 \\
\hline
\end{tabular}

Pearson 상관관계 계수의 해석에 따라 OWAS의 조치단 계와 각 신체 부위별 주관적 불편도의 상관관계를 분석한 결과, 전신과 허리에서 상관계수가 0.404 와 0.499로 나타 났으며, 무릎과 발목에서는 0.233과 0.248로 OWAS의 조 치단계와 전신, 허리, 무릎, 발목의 주관적 불편도의 상관관 계가 낮다고 나타났다. 그리고 OWAS의 조치단계와 각 신 체 부위의 주관적 불편도의 상관관계는 통계적으로 유의하 지 않은 것으로 나타났다 $(p>0.05)$. 이러한 결과를 토대로 OWAS는 작업자의 주관적 불편도를 반영하지 못하고 있다.

$\mathrm{K}-\mathrm{OWAS}$ 의 조치단계와 각 신체 부위별 주관적 불편도 의 상관관계를 분석한 결과, 전신과 허리에서 상관계수가 0.935 와 0.812 로 $\mathrm{K}-\mathrm{OWAS}$ 의 조치단계와 전신, 허리의 상 관관계가 매우 높게 나타났으며, 조치단계와 전신의 주관적 불편도 $(p<0.05)$, 조치단계 점수와 허리의 주관적 불편도의 $(p<0.1)$ 상관관계는 통계적으로 유의한 것으로 나타났다. 
이러한 결과를 토대로 작업 자세 평가 시 상반신(전신, 허 리) 의 평가에 대해서는 $\mathrm{K}-\mathrm{OWAS}$ 가 기존의 OWAS보다 더 적합하다고 판단된다.

결론적으로 전신작업의 평가 시 전신, 허리 등 상반신의 평가에는 $\mathrm{K}-\mathrm{OWAS}$ 를 사용하는 것이 적합하다고 판단된다.

\section{Conclusion}

본 연구는 전신작업 평가 시 주로 사용되는 OWAS의 단 점을 보완하고, 한국인의 작업 현황에 맞게 변형된 OWAS를 개발하기 위하여 새로운 전신작업 평가 기법인 $\mathrm{K}-\mathrm{OWAS}$ 를 제안하였다.

본 연구의 결과로서 OWAS를 이용한 5종류의 작업 자세 에 대한 조치단계와 전신, 허리, 무릎, 발목의 주관적 불편도 의 상관관계는 모두 낮다고 나타났다. 그리고 OWAS의 조 치단계와 전신, 허리, 무릎, 발목의 주관적 불편도의 상관관 계는 통계적으로 유의하지 않은 것으로 나타났다 $(p>0.05)$. 따라서 OWAS는 작업자의 주관적 불편도를 반영하지 못하 고 있다.

$\mathrm{K}-\mathrm{OWAS}$ 를 이용한 5종류의 작업 자세에 대한 조치단 계와 전신, 허리의 주관적 불편도의 상관관계는 전신에서 0.935 , 허리에서 0.812 로 조치단계 점수와 매우 높은 상관 관계를 가져 조치단계 평가에 큰 영향을 미치는 것으로 나 타났다. 그리고 조치단계와 전신의 주관적 불편도 $(p<0.05)$, 조치단계와 허리의 주관적 불편도의 $(p<0.1)$ 상관관계는 통 계적으로 유의한 것으로 나타났기 때문에 상반신(전신, 허 리)의 평가에는 $\mathrm{K}-\mathrm{OWAS}$ 가 적합하다고 판단된다.

$\mathrm{K}-\mathrm{OWAS}$ 는 다른 평가 기법에 비해 특별한 교육을 필요 로 하지 않고 습득 시간이 짧으며, 특별한 도구나 판정표 없 이 각 작업 자세 코드의 합으로 $\mathrm{AC}$ 를 판정할 수 있기 때문 에 작업 현장에서 유용하게 사용할 수 있다는 장점이 있다.

본 연구를 통해서 개발된 새로운 전신작업 평가 기법들을 실제 작업환경에 적용하여 작업자들을 대상으로 타당성 (Validity) 과 신뢰도(Reliability)의 검증이 좀 더 필요하다.

\section{References}

Borg, G., "Psychophysical scaling with applications in physical work and the perception of exertion", Scandinavian Journal of Work, Environment \& Health, 16(1), 55-58, 1990.

Genaidy, A. M., Al-shedi, A. A. and Karwowski, W., "Postural stress analysis in industry", Applied Ergonomics, 25(2), 77-87, 1994.
Grandjean, E. and Hunting, W., "Ergonomics of postures-review of various problems of standing and sitting postures", Applied Ergonomics, 8(3), 135-140, 1977.

Karhu, O., Kansi, P. and Kuorinka, I., "Correcting working postures in industry: a practical method for analysis", Applied Ergonomics, 8(4), 199-201, 1977.

KATS, Report of the Korean Anthropometric Survey for 3D Body Scan Measurement(Size Korea), 2010.

Kee, D. H. and Park, K. H., "Comparison of Posture Classification Schemes of OWAS, RULA and REBA", Journal of the Korean Society of Safety, 20(2), 127-132, 2005.

Kee, D. H., "A Postural Classification Scheme of Upper Body for Females for Quantifying Postural Load of Working Postures", Journal of the Korean Institute of Industrial Engineers, 28(2), 223-231, 2002.

Kim, Y. C., "A Survey on Ergonomic Evaluation Methods of Agricultural Work for Preventing WMSDs", Journal of the Korean Society of Safety, 2011.

Kim, Y. C. and Jung, H. W., "Application of America Ergonomics Program in Korea", Proceeding of the 2000 Fall Conference of the Korean Society of Safety, 2000.

Kim, Y. C. and Jang, E. J., "A Study on Evaluation of the Lower Extremity Supporter using the Borg's scale", Proceeding of the 2008 Spring Conference of Ergonomics Society of Korea, 2008.

Marras, W. S., "Occupational low back disorder causation and control", Ergonomics, 43, 880-902, 2000.

McGill, S. M., "The biomechanical of low back injury-implications on current practice in industry and clinic", Journal of Biomechanics, 30(5), 465-475, 1997.

Moon, C. Y., Na, S. H., Kee, D. H. and Chung, M. K., "Comparison of Observational Posture Evaluation Methods based on Maximum Holding Times", Journal of the Korean Institute of Industrial Engineers, 31(4), 289-296, 2005.

Scott, G. B. and Lambe, N. R., "Working practices in a perchery system, using the OVAKO Working posture Analysing System(OWAS)", Applied Ergonomics, 27(4), 281-284, 1996.

Waters. T. R., Putz-Anderson, V., Garg, A. and Fine, L. J., "Revised NIOSH equation for the design and evaluation of manual lifting tasks", Ergonomics, 36(7), 749-776, 1993.

\section{Author listings}

Yu-Chang Kim: yckim@deu.ac.kr

Highest degree: Ph.D, Department of Industrial Engineering, KAIST Position title: Professor, Department of Industrial Management Engineering, Dong-eui University

Areas of interest: Ergonomics, Industrial Safety, WMSDs, Job Stress, Human Error 
Dae-Su Kim: Daesukim@hotmail.com

Highest degree: Department of Industrial Management Engineering, Dong-eui University

Position title: Master candidate, Department of Industrial Management Engineering, Dong-eui University

Areas of interest: Ergonomics, Industrial Safety, WMSDs, Job Stress, Human Error
Date Received : 2012-01-06

Date Revised :2012-01-16

Date Accepted : 2012-01-18 